\title{
Interest in a Mobile App for Two-Way Risk Communication: A Survey Study Among European Healthcare Professionals and Patients
}

\author{
Sieta T. de Vries ${ }^{1}$ (D) Petra Denig ${ }^{1}$ - Carmen Lasheras Ruiz ${ }^{2}$ - François Houÿez ${ }^{2}$. \\ Lisa Wong ${ }^{3} \cdot$ Alastair Sutcliffe ${ }^{3} \cdot$ Peter G. M. Mol $^{1} \cdot$ on behalf of IMI Web-RADR Work \\ Package 3b Consortium
}

Published online: 2 March 2018

(c) The Author(s) 2018. This article is an open access publication

\begin{abstract}
Introduction Previously, an app has been developed for healthcare professionals (HCPs) and patients to report adverse drug reactions (ADRs) to national medicines agencies and to receive drug safety information.

Objective This study aimed to assess (1) European HCPs' and patients' interest in an app for this two-way risk communication; (2) their preferences and perceptions towards specific app characteristics; and (3) which HCPs and patients are particularly interested in the app. In addition, these aspects were studied specifically for the countries where such an app was already available, i.e. Croatia, The Netherlands, and The UK. Methods European HCPs and patients were asked to complete a web-based survey developed in the context of the Web-Recognizing Adverse Drug Reactions (WebRADR) project. Data on app interest and preferences and perceptions towards app characteristics were analysed descriptively. Logistic regression analyses were conducted to assess the association of $\mathrm{HCP}$ characteristics and patient
\end{abstract}

The members of IMI Web-RADR Work Package $3 \mathrm{~b}$ Consortium are listed in acknowledgements.

Electronic supplementary material The online version of this article (https://doi.org/10.1007/s40264-018-0648-0) contains supplementary material, which is available to authorized users.

Peter G. M. Mol

p.g.m.mol@umcg.nl

1 Department of Clinical Pharmacy and Pharmacology, University of Groningen, University Medical Center Groningen, Groningen, The Netherlands

2 European Organisation for Rare Diseases (Eurordis), Paris, France

3 Population, Policy and Practice Programme, UCL Institute of Child Health, 30 Guilford Street, London WC1N 1EH, UK characteristics on the level of interest in the app (i.e. very interested vs. not/somewhat interested).

Results In total, 399 HCPs and 656 patients completed the survey. About half of the patients (48\%; ranging from 38\% from The Netherlands to $54 \%$ from The UK), and $61 \%$ of the HCPs (ranging from $42 \%$ from The Netherlands to $54 \%$ from The UK) were very interested in the app. A faster means of reporting ADRs and easier access to the reporting form were the main perceived benefits. HCPs and patients who already use a health app were particularly interested in the app (HCPs: odds ratio [OR] 3.52; 95\% confidence interval [CI] 1.96-6.30, patients: OR 1.64; 95\% CI 1.19-2.27).

Conclusions An app is positively perceived by HCPs and patients for reporting ADRs quickly and for receiving drug safety information from national medicines agencies. In particular, HCPs and patients who already use other health apps were interested in the app.

\section{Key Points}

Interest in an app for two-way risk communication (i.e. to report adverse drug reactions [ADRs] to national medicines agencies and to receive drug safety information) is high among healthcare professionals (HCPs) and patients.

The app should be a faster way to report ADRs than conventional reporting options and should preferably offer additional information about drug-drug interactions and previously reported ADRs.

Strategies to disseminate an app on two-way risk communication could focus on targeting HCPs and patients who already use a health app since these persons were particularly interested in the app. 


\section{Introduction}

Healthcare professionals (HCPs) and patients have access to a plethora of health-related mobile apps but not every person is equally interested in such apps. Recently, a health app developed in the context of the Web-Recognizing Adverse Drug Reactions (Web-RADR) project (https:// web-radr.eu/) was added to the available health-related apps. The goal of this app is to provide two-way risk communication, defined as the possibility to report adverse drug reactions (ADRs) to national medicines agencies/ pharmacovigilance centres, and to receive drug safety information from these agencies [1]. Previously, in a qualitative study, we identified various factors that may influence the use of this app and showed that HCPs and patients were generally positive about its development [2]. However, these aspects should be validated in a larger population.

Considering the plethora of new technologies, including apps, theoretical models have been developed attempting to identify factors that influence the uptake of the new technology. An example is the Unified Theory of Acceptance and Use of Technology, which states that user characteristics play a moderating role in the acceptance of technology [3]. This indicates that not every HCP or patient will be interested in the app. Several studies have investigated whether interest in health apps is influenced by characteristics such as age, ethnicity/race, gender, current use of a health app, inability to work, income, educational degree, clinical characteristics or having a family member with a specific disease [4-8]. Although the studies consistently show that older people are generally less interested in health apps than younger people [4-8], the literature is inconclusive about other user characteristics. For instance, Latinos/Hispanics were less interested in one study [6] but more interested in another study [8] than Caucasians/white people. Likewise, one study showed that males were slightly less interested than females [7], whereas another study showed no gender differences [8].

The previous studies conducted in the USA [5-8] or Asia (i.e. Singapore) [4] focused on patients or the general population, and assessed a person's interest in a health app in general [6-8] or in apps to support adherence or selfmanagement $[4,5]$. A recent study about the VigiBIP ${ }^{\circledR}$ app, developed by the Toulouse University Pharmacovigilance Center for two-way risk communication, suggests that patients are interested in the app and that different ADRs may by reported via the app compared with conventional methods [9]. However, more studies on characteristics of HCPs and patients on their interest in apps for communicating health-related issues with national medicines agencies are needed.
The aim of the current study was to assess (1) European HCPs' and patients' interest in an app for two-way risk communication; (2) their preferences and perceptions towards specific characteristics of the app; and (3) which HCPs and patients are particularly interested in such an app. In addition, these aspects were specifically studied for the countries where such an app was already available, i.e. Croatia, The Netherlands and The UK. This knowledge can be used by national medicines agencies in the development or improvement of an app for two-way risk communication and in the development of strategies to inform potential users about the existence of the app.

\section{Methods}

\subsection{Study Design and Survey Development}

In this cross-sectional study, data were collected between July and October 2016 using web-based surveys. Two surveys (i.e. one for HCPs and one for patients) were developed in English by members of the Web-RADR project (see Electronic Supplementary Material 1 and 2 for the HCP and patient survey, respectively). The Englishlanguage surveys were translated by an official translation agency into Croatian, Dutch, French, German, Portuguese and Spanish. Web-RADR members checked whether the translations had the same meaning as the English version. The web-based format of the surveys was created using Unipark software (http://unipark.com/en/). A separate link was available for the HCP and patient survey in each of the languages.

The content of the surveys was based on the results of a qualitative study [2], input from members of other work packages of the Web-RADR project, and various HCP and patient organisations. The patient survey contained questions about ADR reporting in general; their opinion of an app to report ADRs, an app to receive safety information, and an app for two-way risk communication; reporting ADRs through an app of the national medicines agency; safety information and receiving such information through an app; and, finally, some general questions such as age, gender and the country in which they lived at the time of survey completion.

In some questions, the name of the national medicines agency/pharmacovigilance centre was mentioned. The Agenciju za lijekove i medicinske proizvode (HALMED), Nederlands Bijwerkingencentrum (Lareb), Medicines and Health Regulatory Agency (MHRA), l'Agence nationale de sécurité du médicament et des produits de santé (ANSM), Bundesinstitutes für Arzneimittel und Medizinprodukte, Autoridade Nacional do Medicamento e Produtos de Saúde (INFARMED) and la Agencia Española del 
Medicamento y Productos Sanitarios (AEMPS) were mentioned in the Croatian, Dutch, English, French, German, Portuguese and Spanish versions of the survey, respectively.

Participants gave their implied consent to participate in the study by voluntarily completing the survey.

\subsection{Participants and Data Collection}

Any HCP or patient in Europe familiar with mobile apps was eligible to participate in this study. All HCPs were considered to be familiar with apps. Patients were informed that they should only complete the survey if they were familiar with apps. Various channels were used to reach HCPs and patients. For instance, European and national HCP and patient organisations distributed the survey among members via direct e-mail or advertisements on their websites and/or in their newsletters. The survey was also announced on Facebook and Twitter accounts, for instance on the account of the Web-RADR project. Recruitment strategies focused particularly on reaching HCPs and patients in Croatia, The Netherlands and The UK since the Web-RADR app on two-way risk communication was available in these countries at the time of this study. The pharmacovigilance centres in Croatia, The Netherlands and The UK also distributed the survey, for instance by posting a message on their respective websites. To encourage response rates, survey completers had the option to participate in a prize draw to win a $€ 50$ coupon.

\subsection{Outcome Measure: Interest in the App}

The outcome measure of this study was responders' interest in an app for two-way risk communication. Responders were asked to rate on a 4-point Likert scale to what extent they were interested in such an app (Table 1). Responders could also indicate that they did not know whether they had interest in the app.

\subsection{Determinants: App Characteristics}

Expectations and actual characteristics of an app may influence someone's intention to download and use an app [3]. Therefore, responders were asked about their preferences and perceptions regarding an app for two-way risk communication. For this, questions were asked about perceived benefits in using the app, the type of news of interest, interest in other functions in the app and the protection of the app. In addition, responders were asked about their intention to download an app for two-way risk communication.

\subsection{Determinants: Healthcare Professional (HCP)/ Patient Characteristics}

The following HCP characteristics were assessed as determinants for HCPs' interest in an app for two-way risk communication: age, gender, how often they already used health apps and whether they had ever reported an ADR to the national medicines agency. For patients, the following characteristics were assessed: age, gender, educational level, number of medicines, how often they already used health apps, whether they had ever experienced an ADR and whether they were aware they could report ADRs to the national medicines agency (Table 1).

\subsection{Analyses}

Descriptive statistics are presented for HCPs and patients separately. In addition, this is presented for countries in which the app was already available. Completers of the Croatian, Dutch or English version of the survey who indicated they were living in these countries at the time of the survey were included in these country-specific analyses. Differences across these countries were tested using Chi-squared $\left(\chi^{2}\right)$ tests. Three post hoc $\chi^{2}$-tests were conducted in the case of $P<0.05$ to test which countries differed from each other. The Bonferroni correction was applied for these post hoc analyses to correct for multiple testing. This implies that $P$ values $<0.016$ were considered statistically significant.

Logistic regression analyses were conducted to assess associations between responder characteristics and the dichotomised outcome measure, expressing a high interest in the app. For this, being very interested was contrasted with being somewhat or not interested (Table 1). In sensitivity analyses using generalised ordered logit models $[10,11]$, we assessed whether this dichotomisation resulted in a loss of information. Responders were excluded from the logistic regression analyses and generalised ordered logit models when they (1) selected another answer option than male/female on the question about their gender; (2) did not answer or answered 'don't know' on the question about the app interest (outcome variable); or (3) did not answer a question that was used as a determinant in these analyses.

All analyses were conducted using Stata ${ }^{\circledR}$ version 13 (Stata Corp., College Station, TX, USA). Microsoft Excel ${ }^{\circledR}$ 2010 (Microsoft Corp., Redmond, WA, USA) was used for the graphical presentation of the results. 
Table 1 Questions and answer options used as outcome variable and determinants

\begin{tabular}{|c|c|c|c|c|}
\hline Variable & Question & Answer options & Type of variable in analyses & $\begin{array}{l}\text { Analyses of } \\
\text { HCPs/patients }\end{array}$ \\
\hline \multicolumn{5}{|l|}{ Outcome variable } \\
\hline App interest & $\begin{array}{l}\text { In general, how interested would you be in an app of } \\
\text { the }<\text { national medicines agency }>\text { that you can use } \\
\text { for both, reporting side effects/adverse drug } \\
\text { reactions and receiving safety information? }\end{array}$ & $\begin{array}{l}\text { Not interested at all } \\
\text { Somewhat } \\
\text { interested } \\
\text { Interested } \\
\text { Very interested } \\
\text { Don't know }\end{array}$ & $\begin{array}{l}\text { Dichotomous: not/(somewhat) } \\
\text { interested vs. very interested } \\
\text { Don't know } \rightarrow \text { excluded }\end{array}$ & $\begin{array}{l}\text { HCPs and } \\
\text { patients }\end{array}$ \\
\hline \multicolumn{5}{|l|}{ Determinants } \\
\hline Age & What is your age? & Continuous & Continuous & $\begin{array}{l}\text { HCPs and } \\
\text { patients }\end{array}$ \\
\hline Gender & What is your gender? & $\begin{array}{l}\text { Male } \\
\text { Female } \\
\text { Other/prefer not to } \\
\text { say }\end{array}$ & $\begin{array}{l}\text { Dichotomous: male vs. female } \\
\text { Other/prefer not to } \\
\text { say } \rightarrow \text { excluded }\end{array}$ & $\begin{array}{c}\text { HCPs and } \\
\text { patients }\end{array}$ \\
\hline $\begin{array}{l}\text { Educational } \\
\text { level }\end{array}$ & What is your highest level of education completed? & $\begin{array}{l}\text { No formal education } \\
\text { or below } \\
\text { Primary education } \\
\text { Lower secondary } \\
\text { education } \\
\text { Upper secondary } \\
\text { education } \\
\text { Post-secondary but } \\
\text { non-tertiary } \\
\text { education } \\
\text { First stage of } \\
\text { tertiary education } \\
\text { Second stage of } \\
\text { tertiary education }\end{array}$ & $\begin{array}{l}\text { Dichotomous: low/secondary } \\
\text { education vs. tertiary } \\
\text { education (first and second } \\
\text { stage) }\end{array}$ & Patients \\
\hline $\begin{array}{l}\text { Number of } \\
\text { medicines }\end{array}$ & $\begin{array}{l}\text { How many different medicines are prescribed to you } \\
\text { at the moment? }\end{array}$ & $\begin{array}{l}0 \\
1 \\
2 \\
3 \\
4 \\
5 \text { or more }\end{array}$ & $\begin{array}{l}\text { Categorical: } 0 \text { medicines; } 1-4 \\
\text { medicines (reference } \\
\text { category); } \geq 5 \text { medicines }\end{array}$ & Patients \\
\hline $\begin{array}{l}\text { Use health } \\
\text { apps }\end{array}$ & How often do you use a health app? & $\begin{array}{l}\text { Daily } \\
\text { Weekly } \\
\text { Monthly or less } \\
\text { often } \\
\text { Never }\end{array}$ & $\begin{array}{l}\text { Dichotomous: never vs. other } \\
\text { answer options }\end{array}$ & $\begin{array}{l}\text { HCPs and } \\
\text { patients }\end{array}$ \\
\hline $\begin{array}{l}\text { Experience of } \\
\text { ADRs }\end{array}$ & $\begin{array}{l}\text { Have you ever experienced a side effect of a } \\
\text { medicine that you take or have taken in the past? }\end{array}$ & $\begin{array}{l}\text { Yes } \\
\text { No } \\
\text { Don't know/don't } \\
\text { remember }\end{array}$ & $\begin{array}{l}\text { Dichotomous: no/don't know } \\
\text { vs. yes }\end{array}$ & Patients \\
\hline $\begin{array}{l}\text { Awareness of } \\
\text { reporting } \\
\text { ADRs }\end{array}$ & $\begin{array}{l}\text { Are you aware that you can report experienced side } \\
\text { effects to the }<\text { national medicines agency }>\text { ? }\end{array}$ & $\begin{array}{l}\text { Yes } \\
\text { No } \\
\text { I have never heard } \\
\text { of the }<\text { national } \\
\text { medicines } \\
\text { agency }>\end{array}$ & $\begin{array}{l}\text { Dichotomous: no/I have never } \\
\text { heard of the }<\text { national } \\
\text { medicines agency }>\text { vs. yes }\end{array}$ & Patients \\
\hline
\end{tabular}


Table 1 continued

\begin{tabular}{|c|c|c|c|c|}
\hline Variable & Question & Answer options & Type of variable in analyses & $\begin{array}{l}\text { Analyses of } \\
\text { HCPs/patients }\end{array}$ \\
\hline $\begin{array}{l}\text { Report ADR } \\
\text { to national } \\
\text { medicines } \\
\text { agency }\end{array}$ & $\begin{array}{l}\text { Have you ever reported an adverse drug reaction } \\
\text { experienced by your patients to the }<\text { national } \\
\text { medicines agency }>\text { ? }\end{array}$ & $\begin{array}{l}\text { Yes } \\
\text { No } \\
\text { Don't know/don't } \\
\text { remember }\end{array}$ & $\begin{array}{l}\text { Dichotomous: no/don't know } \\
\text { vs. yes }\end{array}$ & HCPs \\
\hline
\end{tabular}

$A D R$ adverse drug reaction, $H C P s$ healthcare professionals

\section{Results}

\subsection{Characteristics of the Responders}

\subsubsection{HCPs}

In total, 399 HCPs completed the survey: 192 were from Croatia, 62 were from The Netherlands, 83 were from The UK and $62(16 \%)$ were from other European countries (i.e. countries where the app was not rolled out) (see Electronic Supplementary Material 3). The age of the responders ranged from 20 to 71 years and most of the responders were women $(68 \%)$. Sixteen percent of the 399 HCPs indicated they had never used a health app. More than half of the HCPs had at least heard about the Web-RADR app.

\subsubsection{Patients}

There were 656 patients who completed the survey, of whom 136 were from Croatia, 187 were from The Netherlands, and 100 were from The UK. The remaining $233(36 \%)$ patients were from other European countries (i.e. countries where the app was not rolled out) (Electronic Supplementary Material 3). The age of the participants ranged from 12 to 89 years and most of the responders were women $(65 \%)$. Nineteen percent of the 656 patients were not prescribed any medicines. Half of the patients indicated they had never used a health app even though they had to be familiar with apps in general to complete the survey, and most were not aware of the Web-RADR app $(77 \%)$.

\subsection{Outcome Measure: Interest in the App}

Responders were generally interested in the app for twoway risk communication (Fig. 1). In total, $61 \%$ of the HCPs were very interested in such an app, which ranged from $42 \%$ in The Netherlands to $66 \%$ in Croatia (Fig. 1a). HCPs were somewhat more interested in the app than patients. About half of the patients (48\%) were very interested in the app, which ranged from $38 \%$ in The Netherlands to 54\% in The UK (Fig. 1b). Interest in an app for two-way risk communication was somewhat higher than interest in an app with single functionality (i.e. reporting of ADRs or receiving safety information).

\subsection{Determinants: App Characteristics}

\subsubsection{Perceived Benefits in Using the App}

With respect to the reporting functionality of the app, most of the HCPs and patients indicated that a faster way to report ADRs and easier access to the ADR reporting form were potential benefits of using the app. These answer options were selected by 83 and $73 \%$ of the HCPs, respectively (Table 2) and by 85 and $72 \%$ of patients, respectively (Table 3 ).

Keeping up-to-date with the latest drug safety news $(84 \%)$ and increasing their drug safety knowledge (76\%) were important benefits perceived by HCPs on using an app. The possibility to select medicines of interest was seen as the least beneficial option for HCPs (47\%) (Table 2). Most of the patients saw it as a benefit that the app would allow them to check whether a symptom has previously been reported as an ADR (72\%) (Table 3).

\subsubsection{Type of News of Interest}

HCPs liked an option to receive news about newly identified drug-drug interactions most $(82 \%)$, followed by information about new indications of a drug $(75 \%)$ (Table 2). They also liked the option to receive news for all approved marketed drugs (37\%). However, the 'work-I preference-specific' answer options (i.e. drugs that they prescribe, drugs related to their work and all drugs they are interested in) were together selected by about $60 \%$ of the HCPs (Table 2). 
Fig. 1 a Healthcare

professionals' interest in an app to report adverse drug reactions (8 responders were excluded; 4 did not complete this question and 4 answered 'I don't know'), to receive safety information (5 responders were excluded; 4 did not complete this questions and 1 answered 'I don't know'), and for both (i.e. two-way risk communication) (1 responder did not complete this question and was excluded). b Patients' interest in an app to report adverse drug reactions (15 responders were excluded; 2 did not complete this question and 13 answered 'I don't know'), to receive safety information (14 responders were excluded; 1 did not complete this question and 13 answered 'I don't know'), and for both (15 responders were excluded; 3 did not complete this question and 12 answered 'I don't know'). *All European responders. ADRs adverse drug reactions

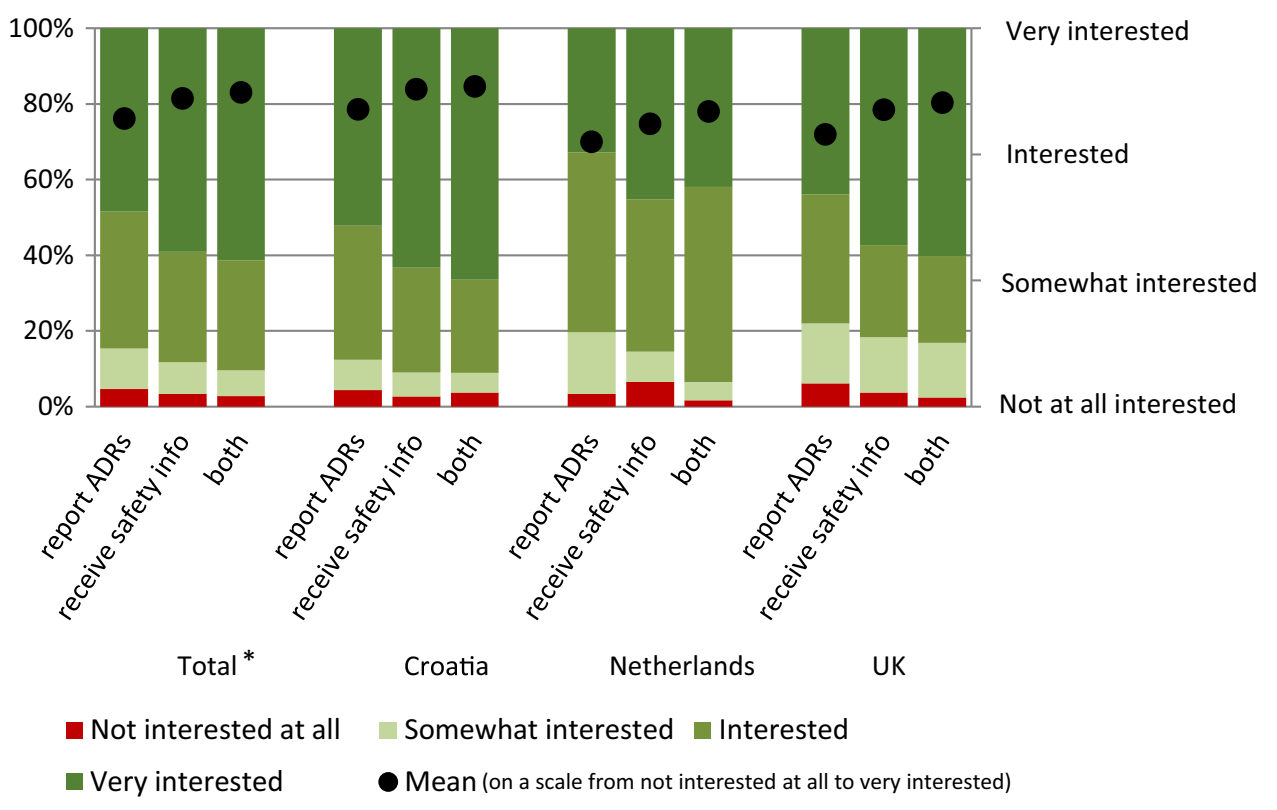

a Healthcare professionals

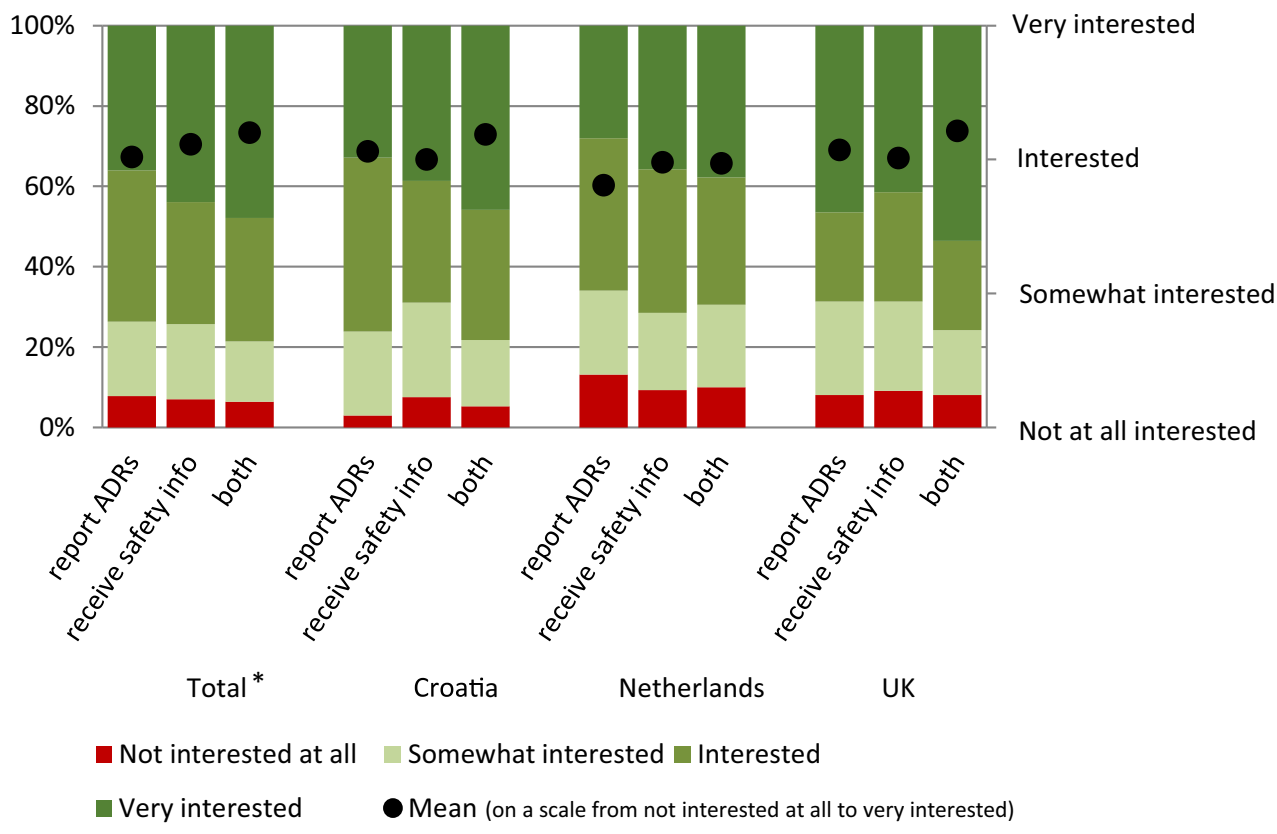

b Patients
Patients liked an option to receive drug safety updates (i.e. each newly identified severe ADR of a drug) most (84\%), followed by newly identified interactions between drugs $(71 \%)$ (Table 3). Only $6 \%$ of the patients liked an option to receive news about all marketed drugs.

\subsubsection{Interest in Other Functions in the App}

Many HCPs and patients selected additional functions that they would like in an app for two-way risk communication. Additional information functions were more often selected than additional reporting functions (Tables 2, 3). For HCPs this included information about known interactions between drugs (76\%), followed by information about how to resolve an ADR (75\%) and an overview of alternative drugs to the one for which an ADR is experienced (71\%). Most patients liked an overview of ADRs previously reported by others $(73 \%)$ and patient information leaflets (72\%). 
Table 2 Healthcare professionals' preferences and perceptions towards various characteristics of the app

\begin{tabular}{|c|c|c|c|c|c|}
\hline & Total $^{\mathrm{a}}$ & Croatia & The Netherlands & UK & $P$-value \\
\hline \multicolumn{6}{|l|}{ Perceived benefits in using the app } \\
\hline \multicolumn{6}{|l|}{ What benefits are there for you in using this app? $?^{\mathrm{b}, \mathrm{c}}$} \\
\hline Faster way to report & $317(83)$ & $152(80)$ & $51(86)$ & $62(84)$ & 0.532 \\
\hline Easier access to ADR report form & $276(73)$ & $131(69)$ & $39(66)$ & $61(82)$ & 0.059 \\
\hline Continue report at a later stage & $232(61)$ & $124(66)$ & $29(49)$ & $49(66)$ & 0.058 \\
\hline Upload a photo & $203(53)$ & $91(48)$ & $34(58)$ & $40(54)$ & 0.383 \\
\hline \multirow[t]{2}{*}{ Store previously reported ADRs } & $200(53)$ & $115(61)$ & $15(25)$ & $37(50)$ & $<0.001$ \\
\hline & & & & & $\begin{array}{l}\text { HR-NL: }<0.001 \\
\text { NL-UK: } 0.004 \\
\text { HR-UK: } 0.109\end{array}$ \\
\hline \multirow[t]{4}{*}{ Complete report offline and send it later } & $179(47)$ & $90(48)$ & $19(32)$ & $39(53)$ & 0.048 \\
\hline & & & & & HR-NL: 0.037 \\
\hline & & & & & NL-UK: 0.018 \\
\hline & & & & & HR-UK: 0.458 \\
\hline \multicolumn{6}{|c|}{ What are the likely benefits in using an app of the $<$ national medicines agency $>$ to receive safety information? $?^{\mathrm{c}, \mathrm{d}}$} \\
\hline It will keep me up-to-date & $318(84)$ & $159(83)$ & $45(80)$ & $68(88)$ & 0.429 \\
\hline \multirow[t]{4}{*}{ Increased knowledge } & $290(76)$ & $155(81)$ & $35(63)$ & $58(75)$ & 0.014 \\
\hline & & & & & HR-NL: 0.004 \\
\hline & & & & & NL-UK: 0.111 \\
\hline & & & & & HR-UK: 0.285 \\
\hline Check whether symptom has been reported as ADR & $248(65)$ & $125(65)$ & $33(59)$ & $55(71)$ & 0.322 \\
\hline \multirow[t]{4}{*}{ Possibility to receive notifications } & $242(64)$ & $112(59)$ & $32(57)$ & $58(75)$ & 0.026 \\
\hline & & & & & HR-NL: 0.842 \\
\hline & & & & & NL-UK: 0.027 \\
\hline & & & & & HR-UK: 0.010 \\
\hline Select medicine of interest & $180(47)$ & $84(44)$ & $19(34)$ & $42(55)$ & 0.058 \\
\hline \multicolumn{6}{|c|}{ Type of news of interest } \\
\hline \multicolumn{6}{|c|}{ What type of news about medicines would be useful to you in an app? $?^{\mathrm{e}, \mathrm{f}}$} \\
\hline \multirow[t]{4}{*}{ Newly identified drug-drug interactions } & $314(82)$ & $166(87)$ & $40(68)$ & $62(79)$ & 0.003 \\
\hline & & & & & HR-NL: 0.001 \\
\hline & & & & & NL-UK: 0.120 \\
\hline & & & & & HR-UK: 0.124 \\
\hline \multirow[t]{4}{*}{ New indications of a drug } & $286(75)$ & $165(86)$ & $28(47)$ & $51(65)$ & $<0.001$ \\
\hline & & & & & HR-NL: $<0.001$ \\
\hline & & & & & NL-UK: 0.035 \\
\hline & & & & & HR-UK: $<0.001$ \\
\hline \multirow[t]{4}{*}{ NCA communications } & $273(71)$ & $139(73)$ & $32(54)$ & $60(77)$ & 0.009 \\
\hline & & & & & HR-NL: 0.007 \\
\hline & & & & & NL-UK: 0.005 \\
\hline & & & & & HR-UK: 0.482 \\
\hline Drugs that are taken off the market & $262(68)$ & $126(66)$ & $37(63)$ & $58(74)$ & 0.288 \\
\hline \multirow[t]{4}{*}{ Changes in the PIL } & $247(64)$ & $130(68)$ & $27(46)$ & $54(69)$ & 0.004 \\
\hline & & & & & HR-NL: 0.002 \\
\hline & & & & & NL-UK: 0.006 \\
\hline & & & & & HR-UK: 0.852 \\
\hline
\end{tabular}


Table 2 continued

\begin{tabular}{|c|c|c|c|c|c|}
\hline & Total $^{\mathrm{a}}$ & Croatia & The Netherlands & UK & $P$-value \\
\hline DHPCs & $245(64)$ & $135(71)$ & $34(58)$ & $42(54)$ & $\begin{array}{l}0.016 \\
\text { HR-NL: } 0.061 \\
\text { NL-UK: } 0.659 \\
\text { HR-UK: } 0.008\end{array}$ \\
\hline Educational materials & $186(49)$ & $106(56)$ & $17(29)$ & $32(41)$ & $\begin{array}{l}0.001 \\
\text { HR-NL: }<0.001 \\
\text { NL-UK: } 0.140 \\
\text { HR-UK: } 0.031\end{array}$ \\
\hline Whether re-assessment is ongoing & $162(42)$ & $74(39)$ & $16(27)$ & $41(53)$ & $\begin{array}{l}0.009 \\
\text { HR-NL: } 0.104 \\
\text { NL-UK: } 0.003 \\
\text { HR-UK: } 0.038\end{array}$ \\
\hline Discontinuation of black triangle & $149(39)$ & $77(40)$ & $9(15)$ & $46(59)$ & $\begin{array}{l}<0.001 \\
\text { HR-NL: }<0.001 \\
\text { NL-UK: }<0.001 \\
\text { HR-UK: } 0.005\end{array}$ \\
\hline \multicolumn{6}{|c|}{ For which medicines would you like to receive news? $?^{\mathrm{g}, \mathrm{h}}$} \\
\hline All approved marketed drugs & $137(37)$ & $61(32)$ & $20(35)$ & $33(45)$ & 0.001 \\
\hline All drugs I am interested in & $72(19)$ & $44(23)$ & $8(14)$ & $9(12)$ & HR-NL: 0.001 \\
\hline Drugs related to my work & $98(26)$ & $60(32)$ & $10(18)$ & $15(20)$ & NL-UK: 0.534 \\
\hline Drugs that I prescribe & $66(18)$ & $23(12)$ & $19(33)$ & $17(23)$ & HR-UK: 0.007 \\
\hline
\end{tabular}

Interest in other functions in the app

Please think about an app that you can use for both reporting ADRs and receiving safety information. Which other information functions would you like in such an app? , $^{\text {i }}$

Interactions between drugs

How to resolve an ADR

Alternative drugs to the one causing the ADR

Drug product information

Overview of previously reported ADRs

Prediction model

Quality alerts

Which other reporting functions would you like in such an app? $?^{\mathrm{f}, \mathrm{j}}$

When the medicine cannot be dispensed

Medicine defects

Medication errors

$\begin{array}{rrr}251(63) & 110(57) & 43(70) \\ 218(55) & 99(52) & 30(49) \\ 154(39) & 72(38) & 15(25)\end{array}$

$\begin{array}{lll}231(68) & 124(72) & 29(64) \\ 216(64) & 105(61) & 23(51) \\ 205(60) & 106(62) & 18(40)\end{array}$

$50(61)$

$<0.001$

HR-NL: $<0.001$

NL-UK: 0.529

HR-UK: $<0.001$

$\begin{array}{lll}296(75) & 148(77) & 42(69) \\ 282(71) & 139(72) & 43(70) \\ 269(68) & 144(75) & 30(49)\end{array}$

$57(70)$

0.270

54 (66) $\quad 0.554$

53 (65) 0.001

HR-NL: $<0.001$

NL-UK: 0.064

HR-UK: 0.080

$\begin{array}{ll}52(63) & 0.163 \\ 49(60) & 0.365\end{array}$

$41(50) \quad 0.008$

HR-NL: 0.064

NL-UK: 0.002

HR-UK: 0.054

$\begin{array}{ll}46(66) & 0.460 \\ 50(71) & 0.083 \\ 44(63) & 0.023\end{array}$

HR-NL: 0.009

NL-UK: 0.016

HR-UK: 0.858 
Table 2 continued

\begin{tabular}{|c|c|c|c|c|c|}
\hline & Total $^{\mathrm{a}}$ & Croatia & The Netherlands & UK & $P$-value \\
\hline \multicolumn{6}{|l|}{ Protection of the app } \\
\hline \multicolumn{6}{|c|}{ How should an app for you to report ADRs and receive safety information of medicines be protected? ${ }^{k, 1}$} \\
\hline Entering an email address and password & $109(30)$ & $63(34)$ & $11(20)$ & $21(29)$ & 0.152 \\
\hline Automatic login & $257(70)$ & $122(66)$ & $43(80)$ & $51(71)$ & \\
\hline \multicolumn{6}{|l|}{ Intention to download the app } \\
\hline \multicolumn{6}{|c|}{ How likely are you to download a free, limited space-taking app to report ADRs and receive safety information of medicines on your device? } \\
\hline Not at all likely & $9(2)$ & $1(1)$ & $1(2)$ & $6(7)$ & $<0.001$ \\
\hline Slightly likely & $32(8)$ & $6(3)$ & $13(21)$ & $8(10)$ & HR-NL: $<0.001$ \\
\hline Moderately likely & $82(21)$ & $35(18)$ & $15(24)$ & $19(23)$ & NL-UK: 0.122 \\
\hline Very likely & $276(69)$ & $150(78)$ & $33(53)$ & $50(60)$ & HR-UK: $<0.001$ \\
\hline
\end{tabular}

Data are given as $n(\%)$

ADRs adverse drug reactions, DHPCs direct healthcare professional communications, $H R$ Croatia, $N C A$ national competent authority, $N L$ Netherlands, PIL patient information leaflet

${ }^{\text {a}}$ All European responders

'The number of responders that do not want to use an app to report ADRs was 12 and the number of responders that selected 'none' was 7. 19 responders selected 'Other'

'Percentages are calculated excluding the responders who selected 'None' and those who selected 'I do not want to use an app to report ADRs/ receive safety information'

d6 responders selected 'None', 13 responders selected 'I do not want to use an app to receive safety information' and 6 selected 'Other'

e 16 responders indicated that they did not want to receive safety information through an app and 10 selected 'Other'

fPercentages are calculated excluding those who selected 'No other information/reporting functions' or 'I do not want to receive safety information through an app'

${ }^{\mathrm{g}} 15$ responders indicated 'None' and 11 responders selected 'Other'

${ }^{\text {h}}$ Percentages are calculated excluding those who selected 'None' and 'Other'

i 2 responders were not interested in any other type of information function and 37 selected 'Other'

${ }^{\mathrm{j}}$ The number of responders not interested in any other type of reporting function was 59 and 20 selected 'Other'

${ }^{\mathrm{k}}$ One responder did not answer this question and 32 responders selected 'Other'

${ }^{1}$ Percentages are calculated excluding the responders who selected 'Other'

\subsubsection{Protection of the App}

Most of the HCPs preferred to use an app for two-way risk communication via an automatic login after entering their e-mail address and password once (70\%) (Table 2). Although most patients also prefer an automatic login, this preference was less pronounced (57\%) (Table 3).

\subsubsection{Intention to Download the App}

In total, $69 \%$ of the HCPs and $52 \%$ of the patients indicated that it is very likely that they will download the app. Only $2 \%$ of the HCPs (Table 2) and 6\% of the patients (Table 3) indicated that this is not likely at all.

\subsubsection{Countries in Which the App was Already Available}

HCPs from Croatia appeared to have more positive views on potential benefits of the app, the addition of other functionalities and the intention to download the app than
HCPs from The Netherlands and The UK (Table 2). HCPs from The Netherlands generally had a more negative view. HCPs from The UK were more positive to receive news in the app about discontinuation of a black triangle for a drug (59 vs. $40 \%$ in Croatia and $15 \%$ in The Netherlands; overall $P<0.001)$ and to receive quality alerts (50 vs. $38 \%$ in Croatia and $25 \%$ in The Netherlands; overall $P=0.008$ ).

Patients from The UK had more positive views on various benefits of using the app than patients from Croatia and The Netherlands (Table 3). Patients from The Netherlands were more negative, particularly regarding potential benefits of continuing an unfinished report at a later moment ( 33 vs. $48 \%$ in Croatia and $56 \%$ in The UK; overall $P=0.001$ ) and of not having to contact a HCP for every symptom they experience ( 24 vs. $50 \%$ in Croatia and $53 \%$ in The UK; overall $P<0.001)$. In addition, they were less positive about patient information leaflets (61 vs. $76 \%$ in both Croatia and The UK; overall $P=0.004$ ), information on where to get help (36 vs. $63 \%$ in Croatia and 
Table 3 Patients' preferences and perceptions towards various characteristics of the app

\begin{tabular}{|c|c|c|c|c|c|}
\hline & Total $^{\mathrm{a}}$ & Croatia & The Netherlands & UK & $P$-value \\
\hline \multicolumn{6}{|l|}{ Perceived benefits in using the app } \\
\hline \multicolumn{6}{|l|}{ What are the likely benefits for you in using this app? $?^{\mathrm{b}, \mathrm{c}}$} \\
\hline Faster way to report & $513(85)$ & $111(85)$ & $138(85)$ & $76(81)$ & 0.592 \\
\hline \multirow[t]{4}{*}{ Easier access to report form } & $434(72)$ & $94(72)$ & $103(64)$ & $75(80)$ & 0.020 \\
\hline & & & & & HR-NL: 0.114 \\
\hline & & & & & NL-UK: 0.007 \\
\hline & & & & & HR-UK: 0.199 \\
\hline Store previous reports & $290(48)$ & $63(48)$ & $70(43)$ & $46(49)$ & 0.569 \\
\hline \multirow[t]{4}{*}{ Upload a photo } & $288(47)$ & $66(51)$ & $63(39)$ & $51(54)$ & 0.030 \\
\hline & & & & & HR-NL: 0.042 \\
\hline & & & & & NL-UK: 0.017 \\
\hline & & & & & HR-UK: 0.606 \\
\hline \multirow[t]{4}{*}{ Continue a report at a later moment } & $264(43)$ & $62(48)$ & $53(33)$ & $53(56)$ & 0.001 \\
\hline & & & & & HR-NL: 0.009 \\
\hline & & & & & NL-UK: $<0.001$ \\
\hline & & & & & HR-UK: 0.199 \\
\hline \multirow[t]{4}{*}{ Complete report offline and send it later } & $262(43)$ & $53(41)$ & $54(33)$ & $50(53)$ & 0.008 \\
\hline & & & & & HR-NL: 0.190 \\
\hline & & & & & NL-UK: 0.002 \\
\hline & & & & & HR-UK: 0.066 \\
\hline \multicolumn{6}{|c|}{ What are the likely benefits for you in using an app of the $<$ national medicines agency $>$ to receive safety information? $?^{\mathrm{c}, \mathrm{d}}$} \\
\hline \multirow[t]{4}{*}{ Check whether symptom has been reported as ADR } & $441(72)$ & $89(69)$ & $106(65)$ & $73(79)$ & 0.048 \\
\hline & & & & & HR-NL: 0.433 \\
\hline & & & & & NL-UK: 0.014 \\
\hline & & & & & HR-UK: 0.086 \\
\hline Increased knowledge & $388(63)$ & $84(65)$ & $90(55)$ & $62(67)$ & 0.079 \\
\hline \multirow[t]{4}{*}{ It will keep me up-to-date } & $378(62)$ & $60(47)$ & $112(68)$ & $66(72)$ & $<0.001$ \\
\hline & & & & & HR-NL: $<0.001$ \\
\hline & & & & & NL-UK: 0.565 \\
\hline & & & & & HR-UK: $<0.001$ \\
\hline \multirow[t]{4}{*}{ Possibility to receive notifications } & $341(56)$ & $42(33)$ & $84(51)$ & $62(67)$ & $<0.001$ \\
\hline & & & & & HR-NL: 0.001 \\
\hline & & & & & NL-UK: 0.012 \\
\hline & & & & & HR-UK: $<0.001$ \\
\hline \multirow[t]{4}{*}{ Select medicines of interest } & $311(51)$ & $51(40)$ & $70(43)$ & $52(57)$ & 0.033 \\
\hline & & & & & HR-NL: 0.587 \\
\hline & & & & & NL-UK: 0.033 \\
\hline & & & & & HR-UK: 0.013 \\
\hline \multirow[t]{4}{*}{ Increased confidence when talking to my HCP } & $283(46)$ & $50(39)$ & $75(46)$ & $53(58)$ & 0.021 \\
\hline & & & & & HR-NL: 0.231 \\
\hline & & & & & NL-UK: 0.068 \\
\hline & & & & & HR-UK: 0.006 \\
\hline \multirow[t]{4}{*}{ No need to contact HCP for every symptom } & $247(40)$ & $65(50)$ & $40(24)$ & $49(53)$ & $<0.001$ \\
\hline & & & & & HR-NL: $<0.001$ \\
\hline & & & & & NL-UK: $<0.001$ \\
\hline & & & & & HR-UK: 0.674 \\
\hline \multicolumn{6}{|c|}{ Type of news of interest } \\
\hline \multicolumn{6}{|c|}{ What type of news about medicines would be useful to you in an app? $?^{\mathrm{e}, \mathrm{j}}$} \\
\hline
\end{tabular}


Table 3 continued

\begin{tabular}{|c|c|c|c|c|c|}
\hline & Total $^{\mathrm{a}}$ & Croatia & The Netherlands & UK & $P$-value \\
\hline Safety updates & $520(84)$ & $104(78)$ & $139(84)$ & $77(85)$ & 0.317 \\
\hline \multirow[t]{4}{*}{ Newly identified drug interactions } & $439(71)$ & $85(64)$ & $105(64)$ & $79(87)$ & $<0.001$ \\
\hline & & & & & HR-NL: 0.961 \\
\hline & & & & & NL-UK: $<0.001$ \\
\hline & & & & & HR-UK: $2009<0.001$ \\
\hline \multirow[t]{4}{*}{ Changes in the PIL } & $421(68)$ & $84(63)$ & $100(61)$ & $71(78)$ & 0.015 \\
\hline & & & & & HR-NL: 0.652 \\
\hline & & & & & NL-UK: 0.005 \\
\hline & & & & & HR-UK: 0.018 \\
\hline New approved used of a drug & $324(53)$ & $69(52)$ & $69(42)$ & $43(47)$ & 0.221 \\
\hline \multirow[t]{4}{*}{ Whether drug review is ongoing } & $310(50)$ & $57(43)$ & $64(39)$ & $55(60)$ & 0.003 \\
\hline & & & & & HR-NL: 0.477 \\
\hline & & & & & NL-UK: 0.001 \\
\hline & & & & & HR-UK: 0.010 \\
\hline \multirow[t]{4}{*}{ News on how to take/store the drug } & $305(49)$ & $72(54)$ & $81(49)$ & $33(36)$ & 0.029 \\
\hline & & & & & HR-NL: 0.386 \\
\hline & & & & & NL-UK: 0.048 \\
\hline & & & & & HR-UK: 0.008 \\
\hline \multirow[t]{4}{*}{ Experiences of other users of the drug } & $292(47)$ & $75(56)$ & $79(48)$ & $33(36)$ & 0.012 \\
\hline & & & & & HR-NL: 0.144 \\
\hline & & & & & NL-UK: 0.073 \\
\hline & & & & & HR-UK: 0.003 \\
\hline Drugs that are temporarily out of stock & $243(39)$ & $45(34)$ & $65(39)$ & $28(31)$ & 0.342 \\
\hline \multicolumn{6}{|c|}{ For which medicines would you like to receive news? ${ }^{\mathrm{g}, \mathrm{h}}$} \\
\hline All approved marketed drugs & $36(6)$ & $10(8)$ & $8(5)$ & $7(8)$ & $<0.001$ \\
\hline All drugs I am interested in & $161(27)$ & $52(40)$ & $20(12)$ & $20(22)$ & HR-NL: $<0.001$ \\
\hline All drugs to treat my disease & $167(28)$ & $35(27)$ & $42(26)$ & $17(19)$ & NL-UK: 0.112 \\
\hline Drugs prescribed to me & $241(40)$ & $33(25)$ & $93(57)$ & $46(51)$ & HR-UK: 0.001 \\
\hline
\end{tabular}

Interest in other functions in the app

Please think about an app that you can use for both reporting side effects and receiving safety information. Which other functions would you like in such an app? $?^{\mathrm{i}, \mathrm{j}}$

Overview of ADRs previously reported

PIL

Store list of medicines

Information on where to get help

Reminder to take medicines
458 (73)

450 (72)

$94(70)$

$102(76)$

$116(67)$

$105(61)$

$84(63)$

$63(36)$

$321(51) \quad 79(59) \quad 54(31)$

$321(51)$

\section{5 (68) $\quad 0.846$ \\ 72 (76) $\quad 0.004$}

HR-NL: 0.004

NL-UK: 0.013

HR-UK: 0.954

$71(75) \quad 0.003$

HR-NL: 0.295

NL-UK: 0.010

HR-UK: 0.001

$56(59)<0.001$

HR-NL: $<0.001$

NL-UK: $<0.001$

HR-UK: 0.567

$54(57)<0.001$

HR-NL: $<0.001$

NL-UK: $<0.001$

HR-UK: 0.750 
Table 3 continued

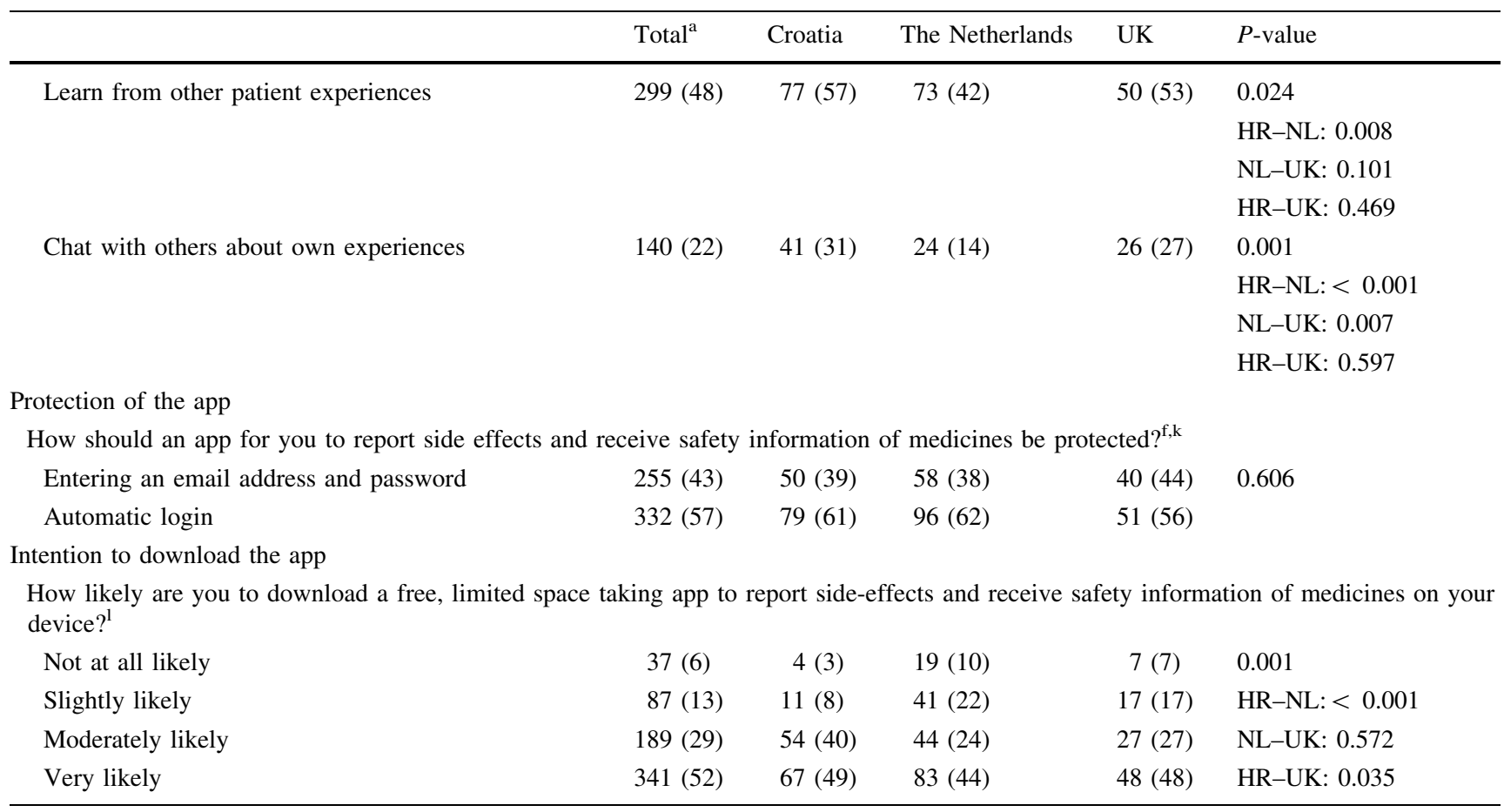

Data are given as $n(\%)$

ADRs adverse drug reactions, DHPCs direct healthcare professional communications, $H R$ Croatia, NCA national competent authority, NL Netherlands, PIL patient information leaflet

${ }^{\mathrm{a}}$ All European responders

${ }^{\mathrm{b}}$ The number of responders who do not want to use an app to report ADRs was 22, the number of responders that selected 'none' was 27 and 36 selected 'Other'

'Percentages are calculated excluding the responders who selected 'None' and those who selected 'I do not want to use an app to report side effects/receive safety information'

d24 responders selected 'None', 20 responders selected 'I do not want to use an app to receive safety information' and 15 selected 'Other'

e 39 responders indicated that they do not want to receive safety information through an app and 29 selected 'Other'

fPercentages are calculated excluding the responders who selected 'Other'

'27 responders indicated 'Not applicable' and 24 responders selected 'Other'

hPercentages are calculated excluding those who selected 'Not applicable' and 'Other'

i 1 responder did not complete this question, 26 were not interested in any other function and 64 selected 'Other'

${ }^{j}$ Percentages are calculated excluding those who selected 'None/No other functions/I do not want to receive safety information through an app'

k 4 responders did not answer this question and 65 responders selected 'Other'

${ }^{1} 2$ responders did not complete this question

$59 \%$ in The UK; overall $P<0.001$ ), a reminder to take medicines ( 31 vs. $59 \%$ in Croatia and $57 \%$ in The UK; overall $P<0.001$ ), and a functionality to chat with others about their own experiences (14 vs. $31 \%$ in Croatia and $27 \%$ in The UK; overall $P=0.001$ ).

\subsection{Determinants: HCP/Patient Characteristics}

Of the 399 HCPs and 656 patients who completed the survey, 390 and 636, respectively, were included in the analyses to assess the association between $\mathrm{HCP} /$ patient characteristics and being interested in the app (Electronic Supplementary Material 4).

\subsubsection{HCP Characteristics}

Of the four determinants included in the analyses of the HCPs, only the use of a health app was significantly associated with interest in the app. HCPs who at least sometimes use a health app were more often very interested than those who never use such an app (odds ratio [OR] 3.52; 95\% confidence interval [CI] 1.96-6.30) (Fig. 2a). The sensitivity analyses per country of interest showed that 
this HCP characteristic was statistically significant for The UK only (OR 9.50; 95\% CI 3.11-29.05) (Electronic Supplementary Material 5). The generalised ordered logit model showed a similar influence of the use of health apps on the different levels of the outcome measure (Electronic Supplementary Material 6).

\subsubsection{Patient Characteristics}

Age and use of health apps were the patient characteristics significantly associated with interest in the app. Older patients were less often very interested in the app than younger patients (OR 0.98; 95\% CI 0.97-0.997). Patients who at least sometimes use a health app were more often very interested than those who never use a health app (OR 1.64; 95\% CI 1.19-2.27) (Fig. 2b). The country-specific analyses showed a statistically significant association of the use of health apps for The Netherlands only (OR 2.20; 95\% CI 1.13-4.27) (Electronic Supplementary Material 7). Additional statistically significant associations were shown for The UK, where patients with a tertiary education level were less often very interested than patients with a low or
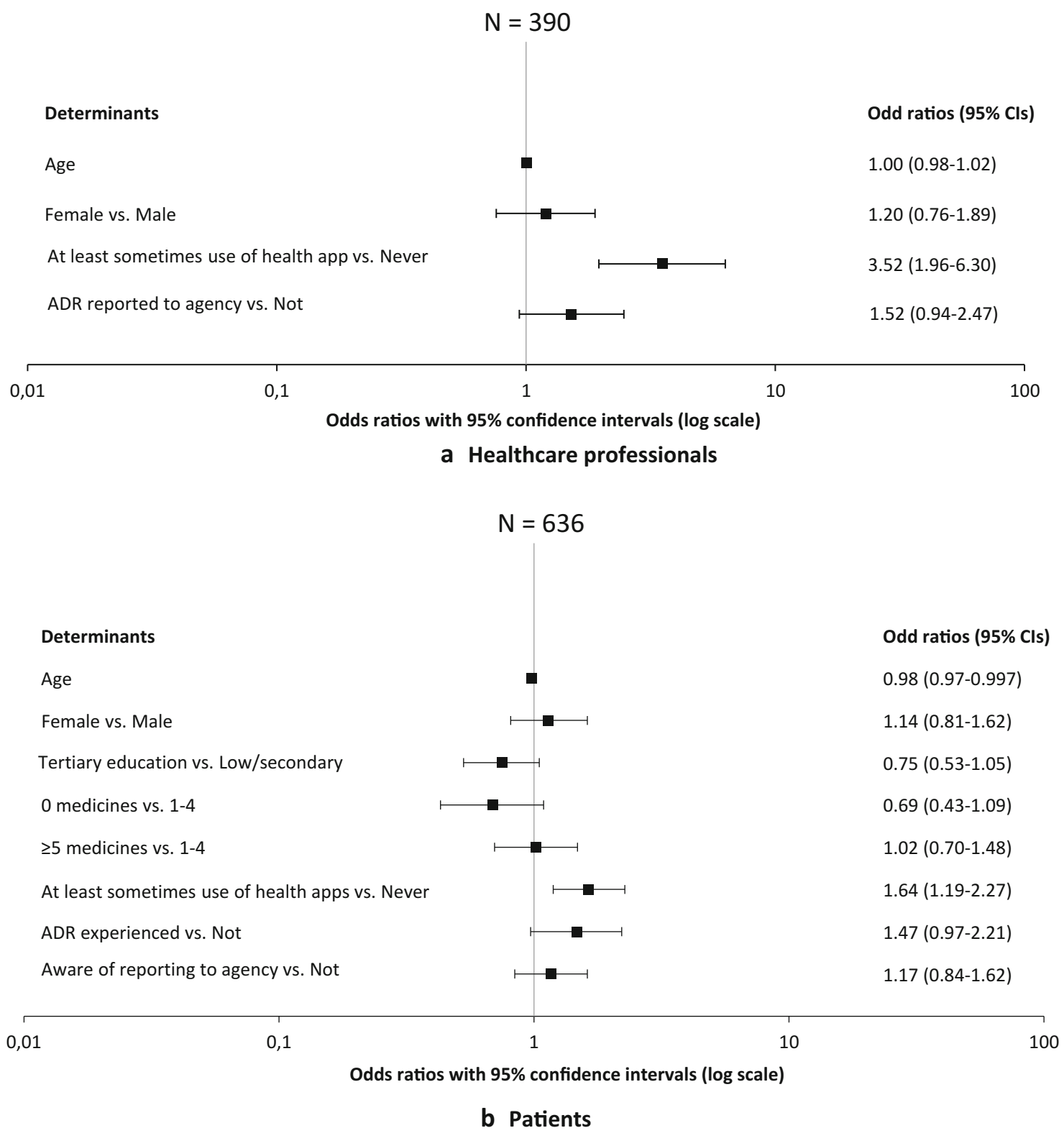

Fig. 2 Odds ratios with $95 \%$ confidence intervals of associations between a healthcare professional characteristics and being very interested in an app for two-way risk communication and $\mathbf{b}$ patient

characteristics and being very interested in this app. $A D R$ adverse drug reaction, $C I$ confidence interval 
secondary education level (OR $0.20 ; 95 \%$ CI $0.05-0.81$ ), and patients who take no medicines were less often very interested than patients who take one to four medicines (OR 0.17; 95\% CI 0.04-0.75). The generalised ordered logit model showed a similar effect of use of health apps on the different levels of the outcome measure but showed different patterns for other characteristics (Electronic Supplementary Material 6).

\section{Discussion}

This study showed that HCPs and patients were generally interested in an app for two-way risk communication and that, in particular, HCPs and patients who already use a health app are more interested in such an app. A main benefit for HCPs and patients of the reporting functionality in the app was that it can make the ADR reporting process faster and easier. Previous studies have shown that lack of time and difficulty in accessing reporting forms are the main barriers for HCPs to spontaneously report ADRs to national pharmacovigilance centres [12-14]. In contrast, literature suggests that patients may be willing to spend more time on reporting an ADR than HCPs [2] and one of the reasons for patients to spontaneously report an ADR is when they have the impression that HCPs have too limited time to accurately report ADRs [15]. However, in this study patients also preferred a reporting tool that is easy and fast to complete.

With respect to the information functionality of the app, HCPs would like the app to keep them up-to-date with the latest news and that it will increase their knowledge about drug safety. In addition, most HCPs liked to receive news about (newly identified) drug-drug interactions. Previously, it has been shown that HCPs' awareness of drug safety issues, for instance those communicated through direct healthcare professional communications (DHPCs), are suboptimal [16] as is their knowledge about drug-drug interactions [17]. Our study suggests that HCPs are aware of their lack of knowledge and that an app could be a tool to improve this.

Patients particularly liked an overview of ADRs previously reported by others, and patient information leaflets as information in an app. They indicated that a main benefit of the app would be to allow them to check whether a symptom was previously reported as an ADR. These findings are in line with previous studies showing that patients are sometimes uncertain about an association between a symptom and a drug [18-21], and may be uncertain about the exact drug causing the symptoms [22]. Providing such information in an app could reduce patients' uncertainty in confirming that their symptoms are caused by the drug(s) they are taking. Also, a previous study showed that one-third of patients did not discuss their medication symptoms with an HCP [23]. Almost half of the patients in our study indicated that the app could increase their confidence when talking to their HCP. This increased certainty about an ADR may improve the patient-HCP conversation about ADRs. In addition, it may increase patient reporting of ADRs to the national pharmacovigilance centres, but future studies will be needed to investigate such effects.

HCPs' and patients' preferences and perceptions towards the characteristics of the app in general were relatively similar. This suggests that the functionality of the app can be similar for HCPs and patients. However, the type of drugs for which responders would like to receive safety information differed between HCPs and patients, as HCPs liked the option to receive information for all drugs more. It should be possible to incorporate such userspecific preferences into the app. In addition, differences in other aspects of the app, such as appropriate terminology for these target groups, need to be considered [2].

Our finding that HCPs and patients who already use a health app are particularly interested in an app for two-way risk communication suggests that, in particular, those HCPs and patients may well be the most receptive group that should be informed about the existence of such an app. This could, for instance, be done via advertisements or a link to the app in other health apps. The high number of responders that liked other functionalities in an app for two-way risk communication also suggests that links to various other health apps may increase its usefulness. Ways to stimulate the interest of non-app users and encouraging their participation could benefit from further investigation.

\subsection{Strengths and Limitations}

A strength of this study is the assessment of interest in the app among both HCPs and patients. In addition, this is a first study assessing the role of user characteristics on the use of an app for two-way risk communication. Although we collected data from a large sample of HCPs and patients, a limitation is that the number of responders per country was still relatively low. Another limitation of this study was its methodology of a cross-sectional survey. We cannot be sure how representative it was of the studied countries. We present data for a subgroup of three countries in which the app was already available, but differences between countries should be interpreted cautiously since the characteristics of the responders differ across these countries. Moreover, the number of responders from countries other than the three countries in which the app was available was low. Therefore, it cannot be assumed that the included population is a representative sample of the European populations. Also, we do not have any 
numbers relating to response rates since HCPs and patients were reached via various channels including advertisements and announcements. Furthermore, survey-answering tendencies may differ across countries, as has been shown previously [24]. Another limitation relates to the assessment of interest in the app. First, we could not use a validated measure to assess interest in the app since, to our knowledge, such a measure is not available. Second, interest is a first step for actually downloading and using the app but its actual use may be influenced by other factors [3]. Therefore, future studies are needed to evaluate the actual use of the app in different countries.

\section{Conclusions}

HCPs and patients in Europe are generally interested in an app for two-way risk communication, which supports its further development. Such an app should support easy and fast reporting of ADRs and provide information about drug-drug interactions and previously reported ADRs to its users. HCPs and patients who already use other health apps are particularly interested in the app. Therefore, dissemination strategies could focus on reaching these HCPs and patients.

Acknowledgements The healthcare professionals and patients who responded to the survey are greatly appreciated. We acknowledge other Web-RADR Work Package 3b members: Raphael van Eemeren, Karin Hace, Sandra Fernandes, Faiza Afzal and Denis Costello.

Author Contributions All authors contributed to the development and formulation of the research question. All authors were involved in distribution of the survey. STdV, PD, and PGMM conducted the analyses. All authors contributed to the interpretation of the data. STdV wrote the manuscript. PD, CLR, FH, LW, AS, and PGMM reviewed and edited the manuscript. All authors have read and approved the final manuscript.

\section{Compliance with Ethical Standards}

Ethical approval The study protocol was submitted to (a member of) an ethics committee in The UK, The Netherlands and Germany. In The UK, approval was obtained from the UCL Research Ethics Committee (Project ID number 6855/001). In The Netherlands, the Medical Ethics Committee of the University Medical Center Groningen (METc UMCG) determined that ethical approval was not needed for this study (reference number M16.191043). In Germany, a review by an ethics committee was not necessary. Therefore, no further approval was deemed necessary for the other countries. All procedures performed in studies involving human participants were in accordance with the ethical standards of the institutional and/or national research committee and with the 1964 Helsinki Declaration and its later amendments or comparable ethical standards.

Funding The Web-RADR project has received support from the Innovative Medicine Initiative Joint Undertaking (http://www.imi. europa.eu) under Grant Agreement n 115632, resources of which are composed of financial contribution from the European Union's
Seventh Framework Programme FP7/2007-2013 and EFPIA companies' in kind contribution, http://www.imi.europa.eu, UK.

Conflict of interest Sieta T. de Vries, Petra Denig, Carmen Lasheras Ruiz, François Houÿez, Lisa Wong, and Alastair Sutcliffe have no conflicts of interest that are directly relevant to the content of this study. Peter G. M. Mol is an employee of the Dutch Medicines Evaluation Board.

Open Access This article is distributed under the terms of the Creative Commons Attribution-NonCommercial 4.0 International License (http://creativecommons.org/licenses/by-nc/4.0/), which permits any noncommercial use, distribution, and reproduction in any medium, provided you give appropriate credit to the original author(s) and the source, provide a link to the Creative Commons license, and indicate if changes were made.

\section{References}

1. Ghosh R, Lewis D. Aims and approaches of Web-RADR: a consortium ensuring reliable ADR reporting via mobile devices and new insights from social media. Expert Opin Drug Saf. 2015;14(12):1845-53.

2. de Vries ST, Wong L, Sutcliffe A, Houyez F, Ruiz CL, Mol PG, et al. Factors influencing the use of a mobile app for reporting adverse drug reactions and receiving safety information: a qualitative study. Drug Saf. 2017;40(5):443-55.

3. Venkatesh V, Morris MG, Gordon B, Davis FD. User acceptance of information technology: toward a unified view. MIS Q. 2003;27(3):425-78.

4. Ali EE, Leow JL, Chew L, Yap KY. Patients' perception of appbased educational and behavioural interventions for enhancing oral anticancer medication adherence. J Cancer Educ. https://doi. org/10.1007/s13187-017-1248-x (Epub 2017 Jul 14).

5. Lucero RJ, Frimpong JA, Fehlberg EA, Bjarnadottir RI, Weaver MT, Cook C, et al. The relationship between individual characteristics and interest in using a mobile phone app for HIV selfmanagement: observational cohort study of people living with HIV. JMIR Mhealth Uhealth. 2017;5(7):e100.

6. Bender MS, Choi J, Arai S, Paul SM, Gonzalez P, Fukuoka Y. Digital technology ownership, usage, and factors predicting downloading health apps among Caucasian, Filipino, Korean, and Latino Americans: the digital link to health survey. JMIR Mhealth Uhealth. 2014;2(4):e43.

7. Carroll JK, Moorhead A, Bond R, LeBlanc WG, Petrella RJ, Fiscella K. Who uses mobile phone health apps and does use matter? A secondary data analytics approach. J Med Internet Res. 2017;19(4):e125.

8. Krebs P, Duncan DT. Health app use among US mobile phone owners: a national survey. JMIR Mhealth Uhealth. 2015;3(4):e101.

9. Montastruc F, Bagheri H, Lacroix I, Damase-Michel C, Chebane L, Rousseau V, et al. Adverse drug reaction reports received through the mobile app, VigiBIP®: a comparison with classical methods of reporting. Drug Saf. https://doi.org/10.1007/s40264017-0630-2 (Epub 2017 Dec 21).

10. Williams R. Generalized ordered logit/partial proportional odds models for ordinal dependent variables. Stata J. 2006;6(1):58-82.

11. Williams R. Understanding and interpreting generalized ordered logit models. J Math Sociol. 2016;40(1):7-20.

12. Vallano A, Cereza G, Pedros C, Agusti A, Danes I, Aguilera C, et al. Obstacles and solutions for spontaneous reporting of 
adverse drug reactions in the hospital. Br J Clin Pharmacol. 2005;60(6):653-8.

13. Lopez-Gonzalez E, Herdeiro MT, Figueiras A. Determinants of under-reporting of adverse drug reactions: a systematic review. Drug Saf. 2009;32(1):19-31.

14. De Angelis A, Colaceci S, Giusti A, Vellone E, Alvaro R. Factors that condition the spontaneous reporting of adverse drug reactions among nurses: an integrative review. J Nurs Manag. 2016;24(2):151-63.

15. Al Dweik R, Stacey D, Kohen D, Yaya S. Factors affecting patient reporting of adverse drug reactions: a systematic review. Br J Clin Pharmacol. 2017;83(4):875-83.

16. Piening S, Haaijer-Ruskamp FM, de Graeff PA, Straus SM, Mol PG. Healthcare professionals' self-reported experiences and preferences related to direct healthcare professional communications: a survey conducted in the Netherlands. Drug Saf. 2012;35(11):1061-72.

17. Glassman PA, Simon B, Belperio P, Lanto A. Improving recognition of drug interactions: benefits and barriers to using automated drug alerts. Med Care. 2002;40(12):1161-71.

18. Chaipichit N, Krska J, Pratipanawatr T, Uchaipichat V, Jarernsiripornkul N. A qualitative study to explore how patients identify and assess symptoms as adverse drug reactions. Eur J Clin Pharmacol. 2014;70(5):607-15.

19. de Vries ST, Mol PG, de Zeeuw D, Haaijer-Ruskamp FM, Denig P. Development and initial validation of a patient-reported adverse drug event questionnaire. Drug Saf. 2013;36(9):765-77.

20. de Vries ST, Haaijer-Ruskamp FM, de Zeeuw D, Denig P. The validity of a patient-reported adverse drug event questionnaire using different recall periods. Qual Life Res. 2014;23(9):2439-45.

21. Britten N. Medication errors: the role of the patient. Br J Clin Pharmacol. 2009;67(6):646-50.

22. de Vries ST, Haaijer-Ruskamp FM, de Zeeuw D, Denig P. Construct and concurrent validity of a patient-reported adverse drug event questionnaire: a cross-sectional study. Health Qual Life Outcomes. 2014;12:103.

23. Weingart SN, Gandhi TK, Seger AC, Seger DL, Borus J, Burdick E, et al. Patient-reported medication symptoms in primary care. Arch Intern Med. 2005;165(2):234-40.

24. Tellis GJ, Chandrasekaran D. Does culture matter? Assessing response biases in cross-national survey research. Int J Res Mark 2010. https://ssrn.com/abstract=1659911. Accessed 30 Jan 2018. 